\title{
O olhar de adolescentes grávidas no ritual
} de passagem menina-mãe

\author{
The look of pregnant adolescents at the girl-mother's ritual \\ passage ritual \\ Carmen Aparecida Cardoso Maia Camargo ${ }^{1}$, \\ Marcio Antonio Ferreira Camargo ${ }^{2}$, Jaciara Aurora de Oliveira ${ }^{3}$, \\ Bianca Rodrigues de Paulo ${ }^{4}$
}

\section{RESUMO}

A gravidez precoce constitui um problema social importante a ser estudado, porque interfere na vida do adolescente, podendo alterar seu desenvolvimento integral e também da família dos mesmos, principalmente em uma camada social vulnerável economicamente. A presente pesquisa teve por objetivo investigar os impactos causados pela gravidez na vida das adolescentes. Trata de uma pesquisa descritiva e exploratória, com abordagem qualitativa. $\mathrm{Na}$ pesquisa de campo, foi utilizada a entrevista semiestruturada, dirigida às adolescentes grávidas de famílias desprovidas de planos de saúde que recebem atendimento no Programa Materno Infantil - PROMAI, de um Hospital no sudoeste de Minas Gerais. Participaram da pesquisa 13 adolescentes. Para a interpretação dos dados das entrevistas utilizou-se a análise de conteúdo. Na maioria das vezes, com a gestação precoce, causa descontentamento da família, as jovens abandonam a escola, sonhos pessoais, consequentemente diminuindo suas chances de desenvolvimento profissional e consequentemente perpetuando o ciclo da pobreza e exclusão social.

Palavras-chave: Gravidez precoce; consequências da gravidez precoce; camadas populares.

\section{ABSTRACT}

Early pregnancy constitutes an important social problem to be studied, because it interferes in the life of the adolescent, and can alter its integral development and also the family of the same, especially in a socially vulnerable social layer. The aim of this research was to investigate the impacts caused by pregnancy in adolescents ' lives. It is a descriptive and exploratory research with a qualitative approach. In the field research, the semi-structured interview was used, aimed at pregnant adolescents of families devoid of health plans that receive care in the Maternal Children Program-PROMAl, of a Hospital in the southwest of Minas Gerais. Thirteen adolescents participated in the study. Content analysis was used to interpret the data of the interviews. Most of the time, with early gestation, causes dissatisfaction of the family, young people abandon school, personal dreams, consequently decreasing their chances \footnotetext{
uemg.br

${ }^{2}$ Idem. E-mail: marcio.camargo@uemg.br

${ }^{3}$ Idem. E-mail: jaciara121@outlook.com

${ }^{4}$ Idem. E-mail: biancarodrigues89@hotmail.com
}

${ }^{1}$ Universidade do Estado de Minas Gerais - UEMG, Belo Horizonte/MG - Brasil. E-mail: carmen.camargo@ 
of professional development and consequently perpetuating the cycle of poverty and Social exclusion.

Keywords: Early pregnancy; consequences of early pregnancy; popular layers.

\section{INTRODUÇÃO}

A gravidez na adolescência é tema bastante discutido e estudado, tendo em vista que uma gravidez precoce pode acarretar diversas consequências à vida das adolescentes e suas famílias.

Partindo da fase de transição da infância à adolescência, pode-se verificar uma fase difícil, em que o adolescente começa a autoconhecer, além de adaptar-se às grandes mudanças, principalmente com o início da puberdade que ocorre trazendo mudanças físicas e emocionais, bem como o despertar da sexualidade.

A imaturidade faz-se presente nessa fase, em que o corpo já alcançou um determinado amadurecimento, porém ainda não está maduro o suficiente para compreender as peculiaridades da vida.

Falar sobre a gravidez na adolescência é desvendar um fenômeno com muitas variantes, que o faz complexo, pois envolvem condições de natureza econômica, psicológica e fisiológica.

Uma condição de grande importância a ser salientada é a gravidez precoce em camadas mais baixas da sociedade, pois, se a gravidez precoce acarreta consequências indesejadas, nessa camada social as consequências são ainda mais expressivas, tendo em vista que o poder econômico é baixo onerando ainda mais o orçamento da família, e gerando um dificultador no desenvolvimento da adolescente.

A problematização do tema partiu da seguinte indagação: quais as consequências causadas pela gravidez precoce na vida da adolescente e em seu meio social?

Sendo assim, o objetivo geral da pesquisa foi analisar o impacto social causado pela gravidez na adolescência de camadas populares matriculadas no Programa MaternoInfantil (PROMAI) da Santa Casa de Misericórdia, localizada no sudoeste de Minas Gerais.

A opção por esta camada social se deu pelo fato de ser um contexto mais vulnerável economicamente, e muitas vezes desprovido de informações de seus direitos sociais, fazendo-se necessária uma atenção especializada de políticas de apoio e projetos, sendo prioridade a pesquisa e o conhecimento para compreender as principais dificuldades do universo do sujeito em estudo.

Para possibilitar essa análise partiram-se dos seguintes objetivos específicos: investigar os impactos sociais da gravidez na vida das adolescentes; verificar a escolaridade das adolescentes grávidas, rendimento financeiro, composição familiar e o vínculo com o respectivo pai da criança e analisar as representações sobre o futuro após o processo vivenciado pela gravidez.

Buscou-se com essa pesquisa conhecer, um pouco mais, sobre os impactos da gravidez na adolescência e trazer uma reflexão para com as políticas públicas 
existentes acerca da necessidade da efetivação das mesmas para uma real proteção social.

\section{REFERENCIAL TEÓRICO}

\subsection{ADOLESCÊNCIA}

O termo "adolescência" é demarcado por diversas características, sendo elas experimentadas em momentos distintos entre um indivíduo e o outro. Essas características são compreendidas como o processo de maturidade, tanto da parte física, como a emocional e psíquica e também a cognitiva, entre outras variações que podem ocorrer nesta fase. Um sinal determinante para a percepção do início da adolescência é a puberdade. (UNICEF, 2012).

\subsection{CARACTERÍSTICAS DA ADOLESCÊNCIA}

De acordo com o Estatuto da Criança e do Adolescente - Lei n. 8.069/1990 é considerado adolescente aquele com idade entre 12 e 18 anos; essa idade é demarcada para fins legais.

Sendo assim, vem explícito em seu art. 2o que: “Considera-se criança, para os efeitos desta Lei, a pessoa até doze anos de idade incompletos, e adolescente aquela entre doze e dezoito anos de idade." (BRASIL, 1990).

Papalia e Feldman (2013) consideram que esse período da adolescência não é manifestado como um episódio singular, mas perdura-se por um longo período de tempo, a denominada adolescência, que abarca mudanças significativas na vida dessas pessoas, como as mudanças físicas e emocionais, podendo variar de acordo com a conjuntura em que se encontra, alterando expressivamente o nível e o tempo dessas mudanças. Essas conjunturas a serem consideradas são o meio social, a cultura a qual está inserida e suas condições econômicas.

De acordo com as autoras supracitadas, a adolescência passa por grandes alterações em seu organismo. Uma fase que traz mudanças muito fortes é a puberdade, que faz parte do sistema biológico e traz consigo o começo da maturação do indivíduo, desencadeando alterações emocionais e psicológicas, que podem durar muito tempo, desde a pré-adolescência e perpassando pela fase adulta. (PAPALIA; FELDMAN, 2013).

A adolescência é uma fase de descobertas, o período da busca consiste em encontrarse. É a etapa de uma busca de pertencimentos, encontrar grupos a que posso participar, ideologias a seguir, e as crenças e os valores que se identificam. Essa é uma passagem inerente à adolescência. São etapas que devem ser perpassadas pelos mesmos, para seu encontro com seu eu. É acarretada por grandes confusões da identidade e quando se iniciam as crises de identidade e os confrontos internos. (ERIKSON, 1950 apud PAPALIA; FELDMAN, 2013).

Assim, a busca pela aprovação de suas atitudes e valores passou a não se desvincular nessa fase, mas sim ganhar fortalecimento na busca de sua identidade. 


\subsection{TRANSFERÊNCIAS FÍSICAS, PSICOLÓGICAS E EMOCIONAIS}

$\mathrm{O}$ adolescente durante sua fase de desenvolvimento sofre diversas mudanças em seu estado biológico, com mudanças físicas, psicológicas e emocional, todas estas interligadas.

Considerando as mudanças físicas, pode-se começar pela fase da puberdade, uma fase intensa na vida dos adolescentes. O início se dá entre 8 e 9 anos, porém, essa faixa etária não é fixa, podendo variar de um indivíduo para outro, começando antes em alguns e tardiamente em outros, com destaque para a diferença de sexo: nos meninos esse processo de puberdade começa depois da menina. (SUSMAN; ROGOL, 2004 apud PAPALIA; FELDMAN, 2013).

No desenvolvimento cognitivo ocorre uma velocidade no processamento de informações, o desenvolvimento de suas habilidades e seu convívio social é amplo. A maneira como lidam com esse grande contingente de mudança é crucial para seu desenvolvimento saudável e favorável, vendo a relação com o seu meio social entre pais, amigos, professores, entre outros um grande apoio em seu desenvolvimento com qualidade. (RAMOS, 2001).

Segundo Papalia e Feldman (2013), o cérebro do adolescente encontra-se em uma fase de desenvolvimento ainda muito imatura. Apesar de sua formação física muito acentuada, seu cérebro ainda responde a ações de forma impulsiva, agindo pelas emoções, ignorando as orientações mais coerentes dos adultos.

Na questão emocional entra o papel importantíssimo do processo de identidade: a importância da amizade e o sentimento de pertencimento. Criam-se nessa época uma fidelidade e companheirismo estritamente necessários à fase da adolescência. A formação de grupos que se identificam é muito comum, ocorrendo o afastamento ou aproximação entre eles. Há uma troca de experiências desse momento de transição, criando uma grande intimidade e confiança. Em um primeiro momento, essa aproximação ocorre majoritariamente entre pessoas do mesmo sexo, partindo num segundo momento para trocas de experiência, aproximação e amizade com adolescentes de sexo oposto. (PAPALIA; FELDMAN, 2013).

Assim, pode-se identificar grande desarranjo na vida dos adolescentes; uma fase conturbada, cheia de desafios, que perduram por um longo período de tempo.

\subsection{SEXUALIDADE}

A sexualidade é enfatizada como o agrupamento de características especiais, externas ou internas, determinadas pelo sexo do indivíduo.

Osório (1992 apud CANO; FERRIARI; GOMES, 2000) afirma que a sexualidade é parte fundamental na formação da identidade do adolescente, já que o mesmo passa por um processo onde sua personalidade está em um estágio conclusivo de construção. É imprescindível afirmar que de fato a adolescência é uma etapa da vida marcada por várias transformações, e nessa conjuntura, depara-se com a sexualidade intrinsecamente ligada a esse processo. 
Segundo Suplicy (1991 apud CANO; FERRIANI; GOMES, 2000), nas últimas décadas, a temática da sexualidade se modificou tão depressa que deixou os pais inseguros a respeito desse tema. Anteriormente, o conceito de certo e errado não eram tão questionáveis pelas famílias nem o que se podia tolerar ou não.

Outro fator eminente, salientado pela autora citada, é que para muitos pais a sexualidade dos filhos exterioriza suas próprias particularidades oprimidas. Atualmente se vive um período complexo para a concepção de um conjunto de conceitos sexuais.

Com a inserção na puberdade prematuramente, ocorre o amadurecimento biológico e não necessariamente acontecerá o mesmo com o amadurecimento intelectual e emocional, o que corroborará para que o adolescente entre antecipadamente na atividade sexual e com efeitos negativos. Adolescentes do sexo feminino mostram uma maior inclinação a ter experimentos sexuais precipitadamente, sendo importante considerar outras conjunturas, como a história e cultura dos adolescentes. (SILVA, 2006).

No Brasil, a idade média da primeira relação sexual é de 16,9 anos para meninas e 15 anos para meninos, sucede-se que esse início imaturo vem desprovido de prudência com a anticoncepção, $26 \%$ da população feminina ficaram grávidas, sendo $40 \%$ gravidez indesejada. (LOPES; MAIA, 1993 apud CANO; FERRIANI; GOMES, 2000).

Uma das causas para a sexualidade precoce é a entrada prematura na fase da puberdade, comportamento ruim na escola, falta de perspectiva com a futura carreira profissional, histórico de violência sexual, a indiferença dos pais, cultura e experiência sexual prematura. A ausência do pai também é um fator contribuinte principalmente nos primeiros anos de idade. (KLEIN; AAP COMMITTEE ON ADOLESCENCE, 2005; ELLIS et al., 2003 apud PAPALIA; FELDMAN, 2013).

A experiência sexual prematura e sem responsabilidades entre os adolescentes colaborará para resultados não positivos na vida dos mesmos, já que é fato a falta de consciência em relação aos métodos contraceptivos. Um desses resultados, como já foi citado e será discorrido nesse trabalho, é a gravidez precoce. Outro fator preponderante é o aumento no número de casos de IST's, como o vírus da AIDS entre muitas outras.

\subsection{CONFLITOS}

O mundo adulto, ao mesmo tempo em que é desejado, também é temido, pois o adolescente vai deixando aos poucos sua natureza infantil e assumindo novos papeis. Este momento é apontado como um estágio essencial na vida humana, porque estabelece o momento decisivo de um crescimento que se deu com o nascimento. As mudanças, tanto físicas quanto da psique, levarão o adolescente a novas formas de se relacionar tanto com os pais quanto com o mundo ao seu redor. Isso será somente possível se ele for se desprendendo de sua identidade, mentalidade, corpo físico infantil. Quando todo esse processo estiver concluído, o adolescente estará pronto a se integrar no mundo "com um novo corpo já maduro e uma imagem corporal formada, que muda sua identidade". Ele ocupa grande parcela de sua energia na 
procura de sua personalidade; essa é a função da adolescência. (CANO; FERRIANI; GOMES, 2000, p.22).

Assim sendo, "da mesma forma que os adolescentes sentem a tensão entre a dependência dos pais e a necessidade de se libertar, os pais querem que os filhos sejam independentes; contudo, acham difícil deixá-los partir." (DENISSEN; VAN AKEN; DUBAS, 2009 apud PAPALIA; FELDMAN, 2013, p.437). O mesmo momento em o adolescente se vê dependente de seus pais, mas anseia por independência, nesse mesmo impasse do outro lado também está a figura dos pais em enxergar a necessidade de independência de seus filhos como também até almejá-la, mas o medo de perdê-los faz com que esse processo seja mais difícil de se absorver.

\section{GRAVIDEZ PRECOCE E AS POLÍTICAS PÚBLICAS}

Sabe-se que a gravidez na adolescência é um problema de saúde pública, que vem despertando interesse das autoridades, mídia e das políticas públicas, pois, enfatiza o problema social do fenômeno, com consequências biológicas, psicológicas e sociais. A gravidez indesejada na adolescência pode trazer impactos para a saúde, educação e pode se tornar um obstáculo ao desenvolvimento de seu pleno potencial. O grande desafio é criar redes de apoio com que venham diminuir os índices, orientar e educar os jovens quanto à prevenção e os problemas decorrentes da gravidez na adolescência.

A fase da adolescência ocorre um grande desarranjo na vida da adolescente e também na sua personalidade. Diante da necessidade de formação da identidade, pode-se entender que a gravidez na adolescência não é um episódio, mas um processo de busca, em que o adolescente acaba por assumir atitudes para o seu autoconhecimento e construção de identidade, desencadeando implicações de ordem social, econômica e psicológica, principalmente pelos adolescentes de camadas populares. (PAPALIA; FELDMAN, 2013).

\subsection{GRAVIDEZ PRECOCE}

Estudar a gravidez na adolescência é tratar de um acontecimento complexo, devido à implicação de vários fatores de ordem social, econômica, psicológica e fisiológica. Portanto, a gravidez precoce constitui um problema social importante a ser estudado, porque interfere na vida do adolescente, alterando seu desenvolvimento integral e também da família dos mesmos.

Dados estatísticos apontam que:

Em 2011, no Brasil, ocorreu 2.913.160 nascimentos; destes, 533.103 de meninas de 15 a 19 anos, e 27.785 de meninas de 10 a 14 anos, representando $18 \%$ e $0,9 \%$, respectivamente, de adolescentes grávidas nesta faixa etária. Apesar dos números indicarem uma diminuição de nascidos vivos nessa faixa etária nos últimos 10 anos, as porcentagens ainda são extremamente preocupantes, com particular atenção para menores de 15 anos. (RNPI, 2013, p.8).

Apesar da grande quantidade de informação sobre sexualidade e métodos contraceptivos, as adolescentes tendem a engravidar, o que acarretam complicações 
sociais, psicológicas e econômicas. As implicações sociais ocorrem porque na maioria das vezes verifica-se evasão escolar e dificuldades na socialização; na parte psicológica porque essa fase é difícil e elas não estão preparadas para viver este momento; e econômica porque quase sempre as famílias assumem a criança e o adolescente, gerando aumento nas despesas da casa. (SANTOS; NOGUEIRA, 2009).

De acordo Moreira et al. (2008), a sexualidade na adolescência vem juntamente com uma grande falta de informação. Os pais, por sua vez, acabam deixando a desejar no que diz respeito à educação sexual dos filhos, resultado da introversão ou até mesmo em um déficit de informações sobre o assunto, o que tornará o jovem um leigo no assunto na temática em questão. A consequência de todo esse processo de desinformação é um preocupante aumento nos índices de casos de gestações não desejadas e infecções sexualmente transmissíveis (IST's).

De acordo com Moreira et al. (2008, p.316) “a gravidez é uma transição que integra o desenvolvimento humano, mas revela complicações ao ocorrer na adolescência, pois envolve a necessidade de reestruturação e reajustamento em várias dimensões". Isso porque a mulher passa assumir novas responsabilidades, um novo papel, passa a se ver e a também a ser vista com outros olhos, o que acontecerá também com o homem, a paternidade o levará para uma transformação do seu desenvolvimento emocional.

O nascimento de um bebê traz consigo grandes mudanças, que não se limitam apenas a questões psicológicas e bioquímicas, mas também a fatores socioeconômicos. Há tempos, a gravidez precoce era resolvida com um casamento às pressas ou exílio para casa de parentes que moravam distantes, "hoje ameaça o futuro dos jovens, considerando os riscos físicos, emocionais e sociais dela decorrente." (MOREIRA et al., 2008, p.316).

O processo da gravidez, na maioria das vezes, é enfrentado com dificuldades, pois a passagem da posição de filha para mãe, "do querer colo para dar colo", é muito intensa e veloz, o que resultará em conflitos sejam internos ou externos em muitos casos dolorosos. A maior parte dessas adolescentes não tem preparo físico, psicológico, social e econômico para enfrentar essa nova etapa, comprometendo assim o exercício de seu papel materno, que vem associado também com a rejeição familiar, contribuindo para a fuga de casa e o abandono dos estudos. Deve-se levar em conta da mesma forma o abandono por parte dos parceiros, muitas vezes adolescentes também. Tais perdas podem trazer consequências emocionais, podendo resultar em riscos para a gravidez. (MOREIRA et al., 2008).

Uma gravidez indesejada e sem assistência pode levar a adolescente a tomar decisões extremas como, por exemplo, abortar o feto em condições inadequadas e ilegais de acordo com a Constituição Brasileira. (MOREIRA et al., 2008, p.316).

\subsection{CONSEQUÊNCIAS DA GRAVIDEZ PRECOCE}

Ao tornar-se mãe, as oportunidades e o desenvolvimento de uma carreira profissional são dificultadas para a adolescente, principalmente com relação aos estudos. 
Dados apontam que o abandono escolar é superior entre as meninas que engravidaram em comparação às que não engravidaram. Estudo do Instituto de Pesquisa Econômica Aplicada (IPEA) realizado em 2009 diz que o percentual do abandono escolar foi de $6,1 \%$ entre meninas de 10 17 anos sem filhos. Já para meninas na mesma faixa etária com filhos, esse percentual saltou para 75,6\%. A educação está diretamente relacionada à taxa de fecundidade, quer dizer, quanto menor o grau de instrução, maior a quantidade de filhos por mulher, podendo chegar a três filhos. (RNPI, 2013, p.27).

Ao falar-se das consequências da gravidez precoce, a variante mais prevalente é a evasão escolar, sendo observada pela maioria dos autores que discorrem sobre esse tema.

Um dos medos das adolescentes é com a autoimagem e com a saúde do feto, medos relativos a função de gerar, alimentar e a hora do parto são bem presentes nessa fase, desencadeando irritação e alteração de humor na grávida.

Ao destacar as consequências da gravidez precoce não se pode deixar de salientar o desenvolvimento da adolescente, pois, nesse momento ela começa a ser vista de outra forma. Deixa de ser a figura frágil e indefesa e passa para a figura de mulher e responsável pela criança. Desta forma, a fase da adolescência é acelerada pela maturidade e a necessidade de assumir responsabilidades para com o bebê, condição essa necessária dentro da mudança de papeis. (MOREIRA et al., 2008).

O fato de a adolescente vir a ultrapassar etapas importantes do ponto de vista do desenvolvimento, em função de uma gestação nessa fase da vida, constitui-se como uma experiência emocionalmente difícil.

Um fator importante a ser considerado é o estado psicológico vivenciado nesse momento. Uma gravidez indesejada pode trazer consequências emocionais muito fortes por ser considerada como falta de responsabilidade e erro; elas tendem a se culpar, podendo acarretar a depressão e outras doenças psicológicas causadas pelo medo de julgamento por parte dos pais ou da sociedade. (MOREIRA et al., 2008).

Dentro do fator saúde, como destaca a Organização das Nações Unidas - ONU (2004 apud UNICEF, 2012, p.22):

(...) na América Latina, um estudo mostra que meninas que dão à luz antes de completar 16 anos têm probabilidade de três a quatro vezes maior de morrer do que as mulheres maiores de 20 anos de idade. Em todos os lugares do mundo, complicações relacionadas a gravidez e ao parto estão entre as principais causas de morte de meninas adolescentes de 15 a 19 anos de idade.

A gravidez precoce tem grandes probabilidades de acarretar problemas de saúde "desenvolver síndromes hipertensivas, partos prematuros, anemia, pré-eclâmpsia, desproporção feto-pélvica, restrição do crescimento fetal (...)" ressaltando também que podem ocorrer sérios problemas decorrentes do aborto, devido às condições precárias que eles são realizados. (MOTA, 2012 apud TABORDA et al., 2014, p.20). 
Dessa forma, a partir de todos os apontamentos, estudar a gravidez na adolescência é tratar de um acontecimento complexo, devido à implicação de vários fatores de ordem social, econômica, psicológica e fisiológica.

\subsection{GRAVIDEZ NAS CAMADAS POPULARES}

A etapa em que ocorre a gravidez na adolescência culmina em situações de grandes batalhas internas e dúvidas. Como foi citada por Figueiró (2002), a gravidez entre adolescentes pode trazer grandes problemas sociais, porém, com mais força às adolescentes vindas de famílias pobres.

Esta camada social faz parte de um contexto mais vulnerável economicamente, e muitas vezes desprovido de informações de seus direitos sociais. Faz-se necessária uma atenção especializada de políticas de apoio e projetos, sendo prioridade a pesquisa e o conhecimento para compreender as principais dificuldades do universo do sujeito em estudo.

A pobreza veta os direitos do adolescente, onde acaba por reproduzir uma situação de vulnerabilidade que fomenta outras e outras vulnerabilidades; essa situação aflige a confiança no futuro dos jovens. (UNICEF, 2012).

A gravidez, como outra expressão da vulnerabilidade, causa grandes e profundos impactos na vida da população jovem, onde está estritamente ligada à evasão escolar, restringindo suas oportunidades no desempenho escolar, oportunidades de formação e crescimento profissional. Afinal, assim como a baixa escolaridade, a gravidez na juventude também é um fomentador do ciclo gerador da perpetuação da pobreza e da exclusão. (UNICEF, 2012).

De acordo com Baraldi, Daud e Almeida (2007), a gravidez na adolescência é frequente em todos os níveis sociais, mas a maior incidência ocorre nas populações de baixa renda, em que a gravidez na adolescência torna-se a porta de entrada para o ciclo da pobreza.

Nas classes mais populares a gravidez precoce, causa uma grande mudança no projeto de vida futura, em que pode ocorrer o perpetuamento da pobreza, educação precária, ausência de perspectiva de vida, lazer e emprego. Nas famílias das adolescentes de classe mais favorável a dificuldade em aceitar a gravidez precoce está ligada à preocupação quando essas jovens derem continuidade em seus estudos, contexto no qual o casamento é deixado para depois do término dos estudos. (TABORDA et al., 2014).

A gravidez, como expressão da vulnerabilidade, causa grandes e profundos impactos na vida da população jovem, restringindo suas oportunidades no desempenho escolar, oportunidade de formação e crescimento profissional. Afinal, assim como a baixa escolaridade, a gravidez na juventude também é um fomentador do ciclo gerador da perpetuação da pobreza e da exclusão. (UNICEF, 2012).

\subsection{AS POLÍTICAS PÚBLICAS}

Ao tratar sobre o tema da gravidez na adolescência nas camadas populares é imprescindível falar sobre políticas públicas, por remeter-se de uma camada da 
população que se encontra em vulnerabilidade, seja econômica ou pelas múltiplas consequências que a gravidez precoce pode acarretar.

As políticas públicas voltadas aos jovens emergiram no Brasil e mundialmente nos anos 90. Esse passo importante teve início com a Lei n. 8.069 de 13 de julho de 1990 o Estatuto da Criança e do Adolescente (ECA) - conferindo ao Estado e à família a responsabilidade de prover qualidade de crescimento íntegro e saudável a essa classe. Isto para garantir prioridade em assistência às crianças e adolescentes pelo serviço público, com a formulação, execução e recursos destinados às Políticas Públicas (PP), pensadas para serem efetuadas de maneira interdisciplinar e intersetorial. Todavia, o ECA desvelou-se limitadamente sua eficiência no que diz respeito à criação de políticas destinadas aos jovens, principalmente a nível municipal, por não existir recognição dos direitos da juventude ou por políticas inconstantes e ineficientes. (GONÇALVES; GARCIA, 2007; OLIVEIRA; MILNITSKY, 2007 apud TEIXEIRA et al., 2013, p.40).

Foi a partir da Constituição Federal de 1988 que muitas mudanças ocorreram no Brasil, principalmente no que diz respeito às políticas públicas, o que até hoje, traz constantes mudanças em programas e projetos do governo. Neste contexto o principal foco das políticas foram os adolescentes de classes menos favorecidas.

As políticas estabelecidas no Brasil não conseguem de uma forma completa prover com as reais precisões e diferenças dos jovens na atualidade, o que assinala os desafios na edificação de ações que possam considerá-las em suas múltiplas dimensões emergindo a necessidade do debate sobre a intersetoriedade. Esse fato revela a imprescindível "e necessária busca de participação efetiva dos jovens na concepção, formulação, acompanhamento e avaliação das práticas, num enfoque integral e interdisciplinar." (ANDRADE; BÓGUS 2010 apud TEIXEIRA et al., 2013, p.38).

Remetendo-se a políticas públicas de saúde para o adolescente, de acordo com Teixeira et al. (2013) pode-se salientar que em 1988 ocorreu a criação do Sistema Único de Saúde - SUS, resultando numa nova orientação do padrão de atenção à saúde. Porém, ainda há busca da totalidade, completude, igualdade e "participação social para o ser adolescente", pois ele deveria ter primazia nas políticas públicas, considerando-se que ele é público-alvo do ECA.

Nesse processo é criado também o Programa de Saúde do Adolescente (PROSAD), trazendo proposições de saúde integral aos jovens. Contudo, suas vertentes revelaram-se principiantes, segmentadas e momentâneas. Outros estudiosos apontam que as metas desse programa eram insuficientes com atuações desconjuntas, sem a participação dos jovens e com ausência, preferência e legitimidade política. (SPOSITO et al., 2006; SPOSITO; CARRANO, 2003 apud TEIXEIRA et al., 2013).

A partir da política de saúde para atenção aos adolescentes, o programa mais recente para a atenção à saúde não somente do jovem mais da família, foi o Programa de Saúde da Família (PSF/ESF), os adolescentes passam a ser vistos como membros da família e redirecionados para ao atendimento geral, desconsiderando suas especificidades e identidades. 
Outros empasses surgiram à saúde dos adolescentes, que não apenas a ineficiência do programa do governo. Um grande problema levantado nas Estratégias de Saúde da Família - ESF's foi o não comparecimento dos jovens nas Unidades Básicas de Saúde (UBS), que as procuram somente em casos de danos físicos, salientando a falta de interesse a atividades oferecidas tanto a nível educativo e preventivo. Sendo assim, é preciso ponderar a importância de se promover uma educação em saúde eficiente, que abranja a prudência, a comunicação reflexiva levando em consideração as individualidades e o meio sociocultural de cada uma desses jovens, para que eles sejam realmente alcançados com a mensagem que será transmitida. (MENDONÇA, 2002; ALVES; BRANDÃO, 2009; DIAS et al., 2010 apud TEIXEIRA et al., 2013, p.41).

Necessário evidenciar que a atenção primária deveria acontecer nas escolas e abranger as famílias e a sociedade através de encontros, reuniões etc. As informações são várias, como a conscientização do início precoce da vida sexual, uso correto dos métodos contraceptivos, diálogo com a família, enfim, o melhor jeito ainda é a prevenção.

É preciso salientar também, que se torna imprescindível o investimento do próprio município em programas ou redes sociais que amparem essas jovens. O apoio social tem a função de amenizar o impacto dos acontecimentos da gravidez que pode afetar de forma negativa a saúde emocional e física das adolescentes, uma vez que é importante sentirem-se confiantes e seguras para que possam atingir certo nível de bem-estar psicológico, contribuindo assim para uma superação positiva dos problemas gerados.

Faz-se necessário que os profissionais que trabalham direto ou indiretamente com esta parcela da população, compreendam os fatores que levam a gravidez precoce, no intuito de realizar um trabalho mais efetivo, com ações de prevenção e reflexão sobre os problemas desencadeados pela gravidez na adolescência.

\section{METODOLOGIA}

\subsection{CARACTERIZAÇÃO DA PESQUISA}

A metodologia utilizada foi à pesquisa descritiva e a exploratória, por descreverem as características da população e o fenômeno em estudo, que é a gravidez na adolescência. Exploratória, por ter como objetivo o conhecimento do fenômeno (a visão e as consequências da gravidez na adolescência) a ser investigada de maneira em que o estudo seja planejado com grande entendimento e precisão.

A pesquisa descritiva busca observar, descrever e explorar aspectos de uma situação que ocorre, buscando o conhecimento sobre o fenômeno estudado. (POLIT; HUNGLER, 1995).

A abordagem metodológica adotada foi a qualitativa. Qualitativa por ser um estudo direcionado à interpretação dos dados subjetivos e quantitativos por caracterizar o grupo estudado em relação a diferentes variáveis. 
O que se aplica ao estudo da história, das relações, das representações, das crenças, das percepções e das opiniões, produtos das interpretações que os seres humanos fazem a respeito de como vivem, constroem seus artefatos e a si mesmos, sentem e pensam.

O trabalho de campo é colocado como uma possibilidade de se aproximar daquilo que se pretende estudar e, concomitantemente, como uma forma de se criar um conhecimento, requer o uso de determinadas técnicas a fim de que se possa estabelecer uma relação propícia com o indivíduo do estudo e, assim, obter dados que satisfaçam o problema da pesquisa. (OLIVEIRA, 2006).

\subsection{CONTEXTO}

O Município pesquisado está localizado no sudoeste de Minas Gerais. De acordo com dados fornecidos pela Secretaria Municipal de Saúde/Coordenação dos ESF's do município, após consulta no Sistema de Informação do Ministério da Saúde - SispréNatal Web, referentes ao período de 2012 a 2015, constatou que foram cadastradas 444 adolescentes grávidas de 10 a 19 anos nos postos de Estratégia de Saúde da Família (ESF). Somente no ano de 2015 foram 205 grávidas cadastradas.

O Município conta com a rede de apoio às adolescentes grávidas, o Programa Materno Infantil - PROMAI da Santa Casa de Misericórdia foi implantado em outubro de 1998, a fim de desenvolver um trabalho multidisciplinar comprometido em alcançar um alto nível de qualidade em saúde do grupo materno-infantil.

A pesquisa foi realizada neste local, onde se faz o acompanhamento de gestantes de risco e gestantes adolescentes. O PROMAI conta com o Programa de Assistência à Adolescente Grávida ASA, voltado exclusivamente à gestante adolescente de toda a rede pública de saúde e tem como objetivo, além de oferecer o controle pré-natal completo, voltado ao incentivo do parto normal e aleitamento materno.

Fazem parte do quadro profissional do PROMAI: psicóloga, terapeuta ocupacional, assistente social, nutricionista, fisioterapeuta, dentista, além de médicos e enfermeiras, tendo por base um acompanhamento sistemático com a equipe multiprofissional de apoio ao pré-natal.

O programa está dividido em 4 módulos: Pré-Natal, Aleitamento Materno, Saúde da Criança e Saúde da Mulher.

\subsection{PARTICIPANTES}

O público alvo da presente pesquisa foram 13 adolescentes que participavam do Programa Materno-Infantil (PROMAI), caracterizando-se principalmente por gestantes e mães carentes, desprovidas de planos de saúde particulares, e que não tinham condições financeiras para seguir um acompanhamento multiprofissional particular ou conveniado. 


\subsection{ASPECTOS ÉTICOS}

Este estudo passou pelo Comitê de Ética em Pesquisa, com parecer sob no 1.598.058. Os participantes e familiares dos pacientes, foram previamente informados a respeito dos objetivos e dos procedimentos da pesquisa, bem como a confiabilidade dos dados e do anonimato da sua colaboração. Todos os participantes assinaram os Termos de Consentimento e Assentimento Livre e Esclarecido, conforme orientações a Resolução n. 466/2012, que regulamenta pesquisas que envolvem seres humanos.

\subsection{COLETA DE DADOS}

O instrumento de coleta de dados foi através da entrevista semiestruturada, formulada em 15 perguntas abertas e fechadas, aplicada às adolescentes grávidas assistidas pelo PROMAI, com a finalidade conhecer melhor o impacto causado pela gravidez, o que cada adolescente sente e pensa, bem como está seu convívio social após a vivência da gravidez. A entrevista semiestruturada pressupõe a apresentação de perguntas previamente formuladas, mas abrem espaços para que o informante possa falar de forma livre sobre o tema. (NETO, 1999 apud OLIVEIRA, 2006).

Uma das pesquisadoras foi autorizada a acompanhar o grupo de adolescentes gestantes pelo período de 1 mês. Nesse período, foi realizada a entrevista com 13 adolescentes de um total de 24 , como critério de inclusão foi a disponibilidade em participar e assinatura dos termos.

A pesquisa foi realizada por meio de entrevista individual, sendo estas gravadas quando autorizadas pela entrevistada.

O método da gravação é muito vantajoso no que se refere ao registro de todas as expressões orais, que não são possíveis escreverem durante a entrevista, deixando o entrevistador a disposição para focar sua atenção no entrevistado. (LUDKE; ANDRÉ, 1986).

\subsection{ANÁLISE DE DADOS}

A análise dos dados objetivou organizar e sumariá-los de forma a obter respostas ao problema proposto para investigação. (GIL, 2002).

Foi utilizada a análise de conteúdo, que para Bardin (1979 apud MINAYO, 2007, p.303) "é um conjunto de técnicas de análise das comunicações visando obter, através de procedimentos sistemáticos e objetivos de descrição do conteúdo das mensagens".

Analisar significa buscar o sentido mais explicativo dos resultados da pesquisa, ler através dos índices, dos percentuais obtidos a partir da medição e tabulação dos dados. (BARROS; LEHFELD, 2003).

\section{RESULTADOS E DISCUSSÕES}

A caracterização encontrada nesse grupo foi de adolescentes jovens. A faixa etária com maior incidência de gravidez é a de 16 e 17 anos, apesar de ser uma diferença pequena que ficou na casa dos $7,65 \%$. 
Com base nos discursos das adolescentes, surgiram quatro categorias experimentais com suas subcategorias, sendo elas: a) aspectos sociais - sendo suas subcategorias relação com o parceiro, a relação familiar, composição familiar escolaridade; b) aspectos econômicos - rendimento familiar, rendimento do parceiro, rendimentos da adolescente; c) aspecto sexual - orientação, vida sexual, prevenção; d) aspectos emocionais - sentimento em relação a gravidez, representações de futuro.

\subsection{ASPECTOS SOCIAIS}

Em relação ao pai da criança, foi observado como ponto positivo que $100 \%$ das garotas alegaram contar com o apoio. Apesar de não demonstrarem clareza ao falar do relacionamento deles, na maioria das vezes os pais dos bebês são jovens mais velhos que as adolescentes numa faixa etária entre 16 a 22 anos, mas ainda sim são muito jovens para a responsabilidade de cuidar de uma criança. Alguns trabalham, mas tem salários que margeiam dois salários mínimos. A maioria também abandonou os estudos e não existe um planejamento em conjunto sobre a criança. Grande parte são apenas namorados, tem contato, mas não possui uma integração. Para ilustrar esses dados, após serem questionadas sobre o relacionamento com o pai do bebê, identificaram-se as seguintes falas:

"Assim... a gente conversa todo dia... de vez em quando a gente se vê..., mas não somos namorados." (E4)

"Mais ou menos... ele me passa muita raiva... somos namorados." (E9)

É possível identificar grande imprecisão para com o futuro da relação, podendo basear-se na imaturidade de ambas as partes. De acordo com os dados encontrados, foi possível observar que a menor idade encontrada foi a de 16 anos somando um total de $15,38 \%$ e a maior idade foi de 25 anos somando 7,69\%. A faixa etária predominante foi a de 17 e 19 anos com um percentual de 23,07\%.

No que se refere ao apoio familiar, a relação antes e depois da notícia sobre a gravidez, o resultado foi de que houve uma boa aceitação familiar, e as reações de preocupação, negação ou tristeza foram apresentadas apenas no começo quando a notícia foi dada. Fato que fica evidente nas falas abaixo:

"Mais tranquilo... agora tudo mudou... a reação deles comigo... mudou totalmente... sei lá." (E3)

"Bem...Depois... ah... mais ou menos... tudo muda eles me acham irresponsável por ter engravidado. Depois meus pais aceitaram, de forma natural." (E7)

Dessa forma, a pesquisa confirma hipóteses anteriores que, como apontam Taborda et al. (2014, p.23) “(...) apesar de a gestação na adolescência, na maior parte das vezes, não ter sido planejada, esta foi aceita independente da classe econômica", tendo um impacto positivo ao apoio familiar que elas puderam contar, mas em contrapartida trouxe uma maior dependência dos seus pais.

Outro aspecto importante de acordo com Nascimento, Xavier e Sá (2011, p.44) é que "a gravidez na adolescência tem causado grande impacto familiar", porque quando se descobre a gravidez, na maioria das vezes, o primeiro membro da família a ser 
sensibilizado é a mãe por ser um fato surpreendente, mas que, no decorrer do tempo expõe paulatinamente resultados positivos, ocasionando numa boa repercussão, em que os membros da família passam a ter uma melhor aceitação do fato ocorrido. Portanto, após descoberta pelos familiares sendo a gravidez desejada ou não, desencadeia uma realidade enfrentada pela adolescente contando com o apoio da família, mas admitindo sua responsabilidade materna, levando em consideração que esse experimento contribuirá para seu aperfeiçoamento.

$\mathrm{Na}$ composição familiar, a pesquisa revelou que existe uma variante estrutural familiar. A maioria das adolescentes tem apenas a mãe; outras o padrasto também no seio familiar e na grande maioria a família ser composta com vários irmãos. Foi notória que na maioria das famílias havia a ausência do pai da adolescência somando 76,92\%.

Foi possível analisar que as famílias são bem numerosas, caracterizando essa composição familiar. O número de irmãos que vivem na casa foi de 1 a 2 irmãos que representaram 53,86\%, de 3 a $4,30,76 \%$ e apenas $15,38 \%$ não tinham irmãos que residiam na mesma casa.

Com relação a escolaridade, a maioria das adolescentes parou de estudar ao descobrir a gravidez somando um total de 53,83\%, porém, todas elas expressaram o desejo de voltar aos estudos e as que continuam a estudar relatavam não querer interromper os estudos.

Sobre a escolaridade do pai da criança, 92,3\% não estudavam mais, podendo ter terminado ou interrompido os estudos e apenas 7,69\% ainda estavam estudando.

\subsection{ASPECTOS ECONÔMICOS}

A segunda categoria, aspectos econômicos, pode-se encontrar resultados relevantes que reafirmam outras pesquisas. Os dados revelam que a maior parte das famílias possui o rendimento de até dois salários mínimos representando $92,30 \%$ do total, o que reforça a ideia de Rangel e Queiroz (2008 apud PATIAS; DIAS, 2011) que afirma que nas camadas mais empobrecidas a gravidez se torna como processo recorrente e natural da vida dessas adolescentes, enquanto as de camadas mais altas as intercorrências de gravidez são menos frequentes e com menos consequências sociais e econômicas.

Os proventos do parceiro ou pai da criança também são baixos, assim como o das famílias, sendo que $76,92 \%$ deles trabalham e $23,07 \%$ não trabalham. Os salários variavam de $R \$ 954,00$ a $R \$ 1.300,00$, ficando também na casa de até 2 salários mínimos.

A adolescente, por sua vez, não representou um número expressivo no quesito trabalho, somando apenas $23,07 \%$ das adolescentes, tendo uma remuneração de $\mathrm{R} \$$ 440,00 a $\mathrm{R} \$ 655,00$ mensais.

Assim, nota-se que são salários baixos, no contexto do trabalho informal sem carteira assinada, e pode-se levantar a hipótese de que sua reinserção no mercado de trabalho será ainda mais difícil após dar à luz a criança. 


\subsection{ASPECTOS SEXUAIS}

Ao que se remete o aspecto sexual, pertencente a terceira categoria, analisou-se nessa categoria três subcategorias, sendo elas: a orientação sexual, a vida sexual e a prevenção sexual.

Em relação ao diálogo familiar sobre sexualidade de maneira geral, pode-se observar que a maioria alegava conversar com os pais sobre o tema, apesar de não demonstrar certeza ao que estavam falando. Dessa forma, 61,53\% disseram que "sim" e 36,46\% disseram que "não" conversavam sobre sexualidade. Das adolescentes que declararam não discutir sobre o assunto, 50\% delas afirmaram ter vergonha de adentrar sobre o tema e $50 \%$ afirmaram não ter intimidade suficiente para falar sobre tal coisa.

Nesse levantamento, verificou-se que o diálogo e orientações sexuais ainda é um processo distante entre pais e filhos. Para Dadoorian (2002), a gestação precoce não pode ser vista isoladamente ou como um acontecimento somente pessoal. Deve ser contextualiza no meio familiar e social da adolescente. Ressalta que as reações de maior ou menor apoio afetivo, social ou econômico que a jovem recebe, serão tão diversificadas quantos forem os meios culturais e as condições socioeconômicas. Quando questionadas se dialogavam sobre sexualidade com seus pais, obtiveram-se algumas repostas, tais como:

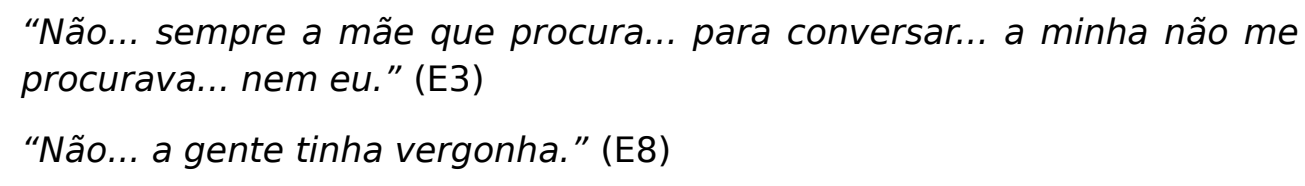

Taborda et al. (2014, p.23) afirma que "quanto ao contexto familiar, nos casos analisados pode se constatar a dificuldade de diálogo nas famílias". É importante salientar que a orientação é parte preponderante na formação sexual dos adolescentes, pois eles precisam de uma fonte segura de informações para evitar gravidez indesejada bem como as IST's, e essa orientação não pode ser estabelecida apenas nas escolas e serviços de saúde, mas dentro do seio familiar, até mesmo como um fortalecimento de vínculos e confiança com os pais.

No que tange à subcategoria relativa à vida sexual, foi possível analisar que a vida sexual começou muito cedo. Entre os dados coletados, a menor idade foi de oito anos seguida pela experiência traumática do estupro e a idade de maior referência foi dos 16 anos. Dentre estas idades, a que obteve mais incidência foi a de treze anos representada por $46,15 \%$. Ressalte-se que $7,69 \%$, equivalente a uma entrevistada não se lembrava da idade em que ocorreu sua disvirginidade.

Ao serem indagadas sobre o uso de métodos contraceptivos, que representa a subcategoria sobre prevenção, vê-se que das 13 adolescentes entrevistadas, 53,85\% delas afirmavam usar algum método de prevenção e 46,15\% afirmaram não usar nenhum método. Dos métodos utilizados, $57,14 \%$ eram pílulas anticoncepcionais e $42,85 \%$ preservativos.

Quando questionadas se usavam algum método de prevenção, a fala abaixo ilustra a resposta: 


\section{"Não... Conheço muito pouco sobre isso." (E2)}

A caracterização encontrada nesse grupo foi de adolescentes jovens. A faixa etária com maior incidência de gravidez é a de 16 e 17 anos, apesar de ser uma diferença pequena que ficou na casa dos $7,65 \%$.

Com base nos discursos das adolescentes, surgiram quatro categorias experimentais com suas subcategorias, sendo elas: a) aspectos sociais - sendo suas subcategorias relação com o parceiro, a relação familiar, composição familiar escolaridade; b) aspectos econômicos - rendimento familiar, rendimento do parceiro, rendimentos da adolescente; c) aspecto sexual - orientação, vida sexual, prevenção; d) aspectos emocionais - sentimento em relação a gravidez, representações de futuro.

\subsection{ASPECTOS EMOCIONAIS}

Essa categoria permite conhecer os aspectos emocionais das adolescentes, sendo possível analisar o seu sentimento em relação à gravidez e também suas expectativas para o futuro.

As adolescentes se sentiram assustadas no momento da descoberta. Alguns pontos chamaram a atenção, principalmente as respostas semelhantes em vários aspectos, entre eles quando foram questionadas se a gravidez era desejada. As respostas, em sua maioria, dizem que foi indesejada, mas verifica-se que as respostas são confusas, misturadas de sentimento e marcada por medos. Conforme relatos constatados abaixo:

"Eu queria e não queria... eu sabia o que estava fazendo... mais não tinha noção do que seria." (E2)

“Eu não queria ter engravidado... Não tá sendo muito fácil... mais não está sendo tão difícil... está sendo bom... eu to gostando." (E4)

Através dessa análise, consegue-se observar que antes da gravidez elas apresentavam um ponto em comum: a fragilidade no processo de formação de sua identidade, e que a gravidez lhes proporcionara um preenchimento desse vazio causado pela crise de identidade. Além da falta de informações, a gravidez pode ser gerada de necessidades inconscientes, podendo ser uma experiência simbólica de renascimento, ou que vem para preencher uma carência afetiva. (MENEZES, 1996 apud FRIZZO; KAHL; OLIVEIRA, 2005, p.14).

Ao serem questionadas de como se sentiram quando souberam da gravidez, as respostas foram as seguintes:

“Com medo... de tudo... de não aguentar... de não conseguir comprar as coisas... medo da minha mãe me mata (risos)." (E2)

"Nossa triste... fiquei com medo... no começo chorei muito." (E11)

Dessa forma, pode-se perceber que em todas as falas, foi possível perceber relatos como medo, sustos e tristezas. 
A representação de futuro gerou grandes incertezas. Durante a entrevista, primeiramente, seguia-se uma grande pausa para reflexão e depois falavam em terminar os estudos e trabalhar ou então não viam perspectiva nenhuma a não ser cuidar da criança.

"Uai... não sei ainda... não penso no futuro... só cuidar do bebê mesmo." (E11)

"Não penso em trabalhar... penso em voltar a estudar... e minha mãe cuidar do bebê é claro (risos)... só isso." (E9)

No decorrer da pesquisa foi possível verificar grande incerteza nas respostas. Assim, tornou-se visível o quanto elas sentiam medo de serem julgadas e o medo em relação ao futuro. A existência de um misto de sentimentos, acabam por acarretar uma falta de perspectiva para com seu próprio futuro.

A prevenção muita das vezes não acontece, como na fala acima. Algumas disseram ter pouco ou nenhum conhecimento sobre os métodos contraceptivos.

\section{CONSIDERAÇÕES FINAIS}

Quando se fala a respeito de gravidez e adolescência está-se tratando de dois acontecimentos complexos, em que ambos trazem à tona intensas e desmedidas transformações à vida do sujeito em desenvolvimento, tendo em vista às mudanças inerentes à dinâmica social e física transcorrentes desse processo.

No que concerne ao referencial teórico desse trabalho, utilizou-se um amplo arcabouço teórico colhido em diversos bancos de dados, como livros físicos e materiais em sites acadêmicos.

Identificou-se que o presente estudo teve como busca primordial o conhecimento da realidade de adolescentes grávidas de uma classe social menos favorecida, pontuando que as famílias que se encontram numa condição fragilizada economicamente são colocadas em situação de vulnerabilidade e consequentemente em risco social, pois não é possível haver vulnerabilidade sem risco.

As dificuldades encontradas por essas adolescentes e suas famílias são diversas, atentando-se para o modelo de saúde vigente no Brasil. Visualizou-se um padrão curativo e não preventivo enfatizando que o melhor caminho para a prevenção da possível ocorrência desse fenômeno seria um trabalho educativo com vistas à proteção sexual não somente para evitar a gravidez indesejada como também as IST's.

A relevância do estudo da temática perfaz-se pelo fato das profundas consequências causadas por esse episódio na vida dos jovens, frisando a questão da evasão escolar, riscos sociais, riscos ligados ao ciclo de vida e riscos econômicos.

É importante ressaltar que se faz necessária, além da educação sexual, torna-se imprescindível trabalhar com uma intensa conscientização no meio dos jovens ressaltando a conjuntura social dos dias atuais, tendo em vista, que as consequências de uma gravidez indesejada no meio dessa dinâmica vigente, pode ser ainda mais expressiva para esse grupo. 
Foi possível extrair da pesquisa resultados satisfatórios, que correspondem a literatura existente, que apesar do apoio das famílias ao decorrer da gravidez, ainda são perceptíveis os empecilhos no processo de formação da adolescente, podendo confirmar que a gravidez na adolescência é um forte fomentador para a evasão escolar, resultando em um dificultador de oportunidades na concretização da sua profissionalização e a dificuldade de inserção no mercado de trabalho, perpetuando assim o ciclo da pobreza.

As políticas públicas para o público específico das adolescentes grávidas ainda são ineficientes observando-se que o atendimento é voltado na maioria das vezes apenas para a saúde, e não para sua reinserção e readaptação na sociedade, porém não pode deixar de salientar o viés encontrado na pesquisa, em que o PROMAI, local que foi realizada a coleta dos dados, conta com o atendimento de planejamento familiar, sendo informado pela psicóloga que poucas jovens aderiam a esse programa.

\section{REFERÊNCIAS}

BARALDI, A. C. P.; DAUD, Z. P.; ALMEIDA, A. M.; GOMES, F. A.; NAKANO, A. M. S. Gravidez na adolescência: estudo comparativo das usuárias das maternidades públicas e privadas. Revista Latino-Americana de Enfermagem, Ribeirão Preto, v.15, n.esp., p.799-805, out. 2007.

BARRoS, A. J. P. de; LEHFELD, N. A. S. Projeto de pesquisa: propostas metodológicas. 12. ed. Petrópolis: Vozes, 2003.

BRASIL. Lei n. 8.069 de 13 jul. 1990. Estatuto da criança e do adolescente. Brasília, Diário Oficial da União, 16 jul. 1990.

BRASIL. Lei n. 8.662, de 7 jun. 1993. Dispõe sobre a profissão de Assistente Social e dá outras providências. Brasília, Diário Oficial da União, 8 jul. 1993. Disponível em: <http://www.planalto.gov.br/ccivil_03/LEIS/L8662.htm>. Acesso em: 13 jul. 2018.

BRASIL, M. S. Normas de atenção à saúde do adolescente: bases pragmáticas. Brasília, Secretaria Executiva. Coordenação da Saúde Criança e Adolescente, 1996.

CANO, M. A. T.; FERRIANI, M. G. C.; GOMES, R. Sexualidade na adolescência: um estudo bibliográfico. Revista Latino-Americana de Enfermagem, Ribeirão Preto, v.8, n.2, p.18-24, abr. 2000.

DADOORIAN, D. Gravidez na adolescência: um novo olhar. Psicologia: Ciência e Profissão, Brasília, v.23, n.1, p.84-91, mar. 2003.

FIGUEIRÓ, A. C. Condições de vida e saúde reprodutiva de adolescentes residentes na comunidade de Roda de Fogo, Recife. Revista Brasileira de Saúde Materno Infantil, Recife, v.2, n.3, p.291-302, set./dez. 2002.

FRIZZO, G.; KAHL, M.; OLIVEIRA, E. Aspectos psicológicos da gravidez na adolescência. Psico, Porto Alegre, v.36, n.1, p.13-20, jan./abr. 2005.

GIL, A. C. Como elaborar projetos de pesquisa. 4. ed. São Paulo: Atlas, 2002. 
IBGE. Instituto Brasileiro de Geografia e Estatística. Síntese de indicadores sociais: uma análise das condições de vida da população brasileira 2014. Rio de Janeiro: IBGE, 2014.

LUDKE, M.; ANDRÉ, M. E. D. A. Métodos de coletas de dados, observação, entrevista e análise documental. In: LUDKE, M.; ANDRÉ, M. E. D. A. Pesquisa em educação: abordagens qualitativas. São Paulo: EPU, 1986. cap.3, p.25-38.

MOREIRA, T. M. M.; VIANA, D. S.; QUEIROZ, M. V. O.; JORGE, M. S. B. Conflitos vivenciados pelas adolescentes com a descoberta da gravidez. Revista da Escola de Enfermagem da USP, São Paulo, v.42, n.2, p.312-320, 2008.

MINAYO, M. C. S. O desafio do conhecimento: pesquisa qualitativa em saúde. 10. ed. São Paulo: Hucitec, 2007.

NASCIMENTO, M. G.; XAVIER, P. F.; SÁ, R. D. P. Adolescentes grávidas: a vivência no âmbito familiar e social. Rev. Adolescência e Saúde, Rio de Janeiro, v.8, n.4, p.4147, out./dez. 2011.

OLIVEIRA, C. M. C. T. Adolescentes grávidas assistidas pelo Conselho Tutelar dos Direitos da Criança e do Adolescente de Piumhi. 2006. Monografia (Graduação em Serviço Social) - Universidade do Estado de Minas Gerais, Belo Horizonte, 2006.

PAPALIA, D. E.; FELDMAN, R. D. Desenvolvimento humano. Tradução de Cristina Monteiro e Mauro de Campos Silva. 12. ed. Porto Alegre: AMGH, 2013.

PATIAS, N. D.; DIAS, A. C. G. Fatores que tornam adolescentes vulneráveis à ocorrência de gestação. Revista Adolescência e Saúde, Rio de Janeiro, v.8, n.2, p.40-45, abr./jun. 2011.

POLIT, D. F., HUNGLER, B. P. Fundamentos de pesquisa em enfermagem. 3. ed. Porto Alegre: Artes Médicas, 1995.

RAMOS, F. R. S.; PEREIRA, S. M., ROCHA, C. R. M. Adolescer: compreender, atuar e acolher. 2. ed. Brasília: ABEn, 2001.

RNPI. Rede Nacional da Primeira Infância (RNPI). Primeira Infância e gravidez na Adolescência (Cartilha). Secretaria Executiva. Biênio 2013/2014. Instituto da Infância (INFA), 2013.

SANTOS, C. A. C.; NOGUEIRA, K. T. Gravidez na adolescência: falta de informação?

Revista Adolescência e Saúde, Rio de Janeiro, v.6, n.1, p.48-56, abr. 2009.

SILVA, M. F. Sexualidade e gravidez na adolescência. 2006. 36 f. Monografia (Especialização em Atenção Básica em Saúde da Família) - Universidade Federal de Minas Gerais, Belo Horizonte, 2006.

TABORDA, J. A.; SILVA, F. C.; ULBRICHT, L.; NEVES, E. B. Consequência da gravidez na adolescência para as meninas considerando-se as diferenças socioeconômicas entre elas. Cadernos de Saúde Coletiva, Rio de Janeiro, v.22, n.1, p.16-24, mar. 2014. 


\section{Revista Thema}

v.17

TEIXEIRA, S. C. R.; SILVA, L. W. S.; TEIXEIRA, M. A. Políticas pública de atenção às adolescentes grávidas - uma revisão bibliográfica. Adolescência e Saúde, Rio de Janeiro, v.10, n.1, p.37-44, jan./mar. 2013.

UNICEF. Fundo das Nações Unidas para a Infância. O direito de ser adolescente: oportunidade para reduzir vulnerabilidades e superar desigualdades. Brasília: UNICEF, 2012.

\section{AGRADECIMENTOS}

À Universidade do Estado de Minas Gerais (UEMG/ PAPq) pelo apoio durante a pesquisa. 